\title{
MODELO GENERATIVO COMO GUIA PARA CRIAÇÃO DA EQUIPE DE MEDIAÇÃO NO INSTITUTO NOOS
}

\author{
GENERATIVE MODEL AS GUIDE FOR CREATION OF THE MEDIATION TEAM \\ AT THE NOOS INSTITUTE
}

ANA LUISA ALMEIDA PRADO DE ANDRADE COUTINHO

\section{MARIA GABRIELA MANTAUT LEIFERT}

Instituto Noos São Paulo/SP, Brasil
RESUMO: Orientado pelas premissas da perspectiva generativa, este artigo relata a criação do Núcleo de Mediação Transformativa no Instituto Noos. A Perspectiva Generativa é uma das abordagens oriundas da teoria sistêmica e dos novos paradigmas pós-modernos. Tecendo uma dança entre teoria e ação, apresentamos os momentos generativos na criação e implementação do Núcleo de Mediação, enaltecendo o foco no recurso nas competências e valores das pessoas. Temos como objetivo demonstrar como as premissas da prática generativa favorecem a formação da equipe de trabalho e da intervisão (supervisão). Acreditamos que, ao proporcionar um ambiente relacional onde cuidamos de nossos colaboradores de forma horizontal, observando os aspectos éticos, das interações, envolvendo a todos em um clima de acolhimento e participação colaborativa, auxiliamos no melhor atendimento de nossos clientes. A partir desta postura criamos condições de fomentar um grupo de trabalho que se autorregule no modelo de uma comunidade de prática e comunidade de aprendizagem, a fim de estimular a produção de conhecimento e promover melhores práticas no atendimento em Mediação.

PALAVRAS-CHAVE: Novos paradigmas; Perspectiva generativa; Núcleo de mediação; Comunidade de prática; Comunidade de aprendizagem.
ABSTRACT: Guided by the premises of the generative perspective, this work reports the creation of the Nucleus of Transformative Mediation at the Instituto Noos. The Generative Perspective is one of the approaches derived from systemic theory and new postmodern paradigms. Weaving a dance between theory and action, we present the generative moments in the creation and implementation of the Nucleus of Mediation, highlighting the focus on the resource, on the skills and values of the people. We aim to demonstrate, as the premises of generative practice favor the formation of the work team and the supervision. We believe that by providing a relational environment where we take care of our partners horizontally, observing ethical aspects, interactions, involving everyone in a welcoming and collaborative participation environment, we assist in the best service of our clients. From this position we create conditions to foster a work group that is self-regulated in the model of a practice and learning community, in order to stimulate the production of knowledge to promote better practices in the service in Mediation.

KEYWORDS: New paradigms; Generative perspective; Mediation nucleus; Community of practice and learning community.
Recebido em: 18/12/2018 Aprovado em: 25/01/2019

\section{INTRODUÇÃO}

Apresentamos neste trabalho o nascedouro do projeto de Mediação do Instituto Noos, desde a formação da equipe até sua implementação e consolidação como grupo de trabalho e grupo de aprendizagem. Faremos um enlace entre nossa prática no processo de constituição do núcleo e os pressupostos teóricos que norteiam a abordagem generativa: foco especial no diálogo, entendido como 
um espaço de coordenação e criação conjunta de significados entre os participantes, englobando a complexidade da narrativa, o conteúdo, o tom, a voz e tempo verbal. Foco nos recursos, nas competências e nos valores das pessoas e/ou organizações que estão envolvidas em um processo. Favorece um agenciamento pessoal que capacita as pessoas a enfrentar desafios e inovar (Schnitman, 2016).

A fim de contextualizar onde o trabalho está sendo desenvolvido, apresentamos o Instituto Noos, contando um pouco de sua origem, história e trajetória. Em seguida discutimos as questões éticas no trabalho com pessoas, pois consideramos de fundamental importância esclarecer quais as nossas premissas sobre atendimento e pesquisa com seres humanos, a fim de partilhar um campo comum de entendimento. Após esses preâmbulos apresentamos a formação do Núcleo de trabalho, bem como as características do estilo de supervisão que adotamos (intervisão).

Em seguida, traçamos um paralelo entre a formação e implementação de nossa equipe de trabalho com o modelo de grupo autogerido proposto no desenho da comunidade de prática e comunidade de aprendizagem (García \& Russo, 2012). Entendemos a comunidade de prática como a intenção de um grupo de pessoas de compartilhar ativa e criativamente um espaço de práticas e experiências, no qual elaboram seus próprios mecanismos de confiança que permitem o fluir de ideias. Um espaço de troca que combina prática, aprendizado e inovação.

Escrever este texto reflete nosso contentamento em vislumbrarmos como a prática generativa está representada na matriz da criação de nosso projeto e na formação e implementação do Núcleo de Mediação. Além disto, nos remete à formação de grupo como um processo de aprendizagem em ação, em um movimento contínuo com muitas idas e vindas, com situações de cegueira e luz, em um constante caminhar para algum ponto no futuro, alicerçado no presente e com as marcas do passado.

\section{O INSTITUTO NOOS COMO NOSSO LOCAL DE PERTENCIMENTO E INTERLOCUÇÃO}

O Instituto Noos é uma organização civil, sem fins lucrativos, que tem por objetivo o desenvolvimento e a difusão de práticas sociais sistêmicas voltadas para a promoção da saúde dos relacionamentos nas famílias e nas comunidades. Foi fundado no Rio de Janeiro há 24 anos, por profissionais das ciências humanas, sociais e da saúde.

O referencial teórico adotado nos trabalhos desenvolvidos no Instituto é a Perspectiva Sistêmica com a postura crítica do Construcionismo Social. Esse olhar para realidade reflete a crença de que fazemos parte de uma rede de relações interligadas e que qualquer intervenção tem que considerar o contexto em que ocorre e as interações presentes.

Em 2018, o Instituto Noos do Rio de Janeiro encerra suas atividades e transfere sua sede para São Paulo, sob a direção de Helena Maffei Cruz, que, junto com sua equipe, assume o compromisso de dar continuidade à trajetória de sucesso e reconhecimento nacional e internacional que o Instituto conquistou a partir de sua sede no Rio de Janeiro no decorrer destes 24 anos, tendo como valores norteadores honestidade, compromisso, espírito colaborativo e respeito.

A Clínica Social foi a primeira atividade desenvolvida na nova sede, oferecendo atendimento a famílias e ca- 
sais encaminhados, entre outros, pelas instituições daquele território. Em seguida, uma equipe de mediadores que compartilha da missão do Instituto organiza um núcleo de mediação por perceber que surgia a possibilidade de ampliar a oferta de atendimentos para outras demandas.

Para a criação desse núcleo de trabalho em mediação, adotamos pressupostos teóricos considerados pós-modernos, isto é, desenvolvidos dentro de novos paradigmas quanto à construção da realidade na linguagem e nas interações sociais, como teoria sistêmica, construcionismo social e as práticas generativas, que têm como premissa central trabalhar com o saber do cliente e seus recursos, gerando novas possibilidades inovadoras de ação. Os coordenadores dessa equipe, juntamente com a diretora do instituto, professora Helena Maffei Cruz, participaram do Diplomado em Práticas Generativas 2016 e, portanto, todos são familiarizados com essa abordagem.

\section{A ÉTICA RELACIONAL NA PRÁTICA DO TRABALHO COM PESSOAS}

Estamos vivendo um momento histórico de muitos antagonismos. De um lado os avanços tecnológicos e científicos nos levam a vislumbrar a possibilidade de uma nova humanidade. Do outro lado, posturas políticas e ideológicas radicais colocam em risco todos os avanços sociais produzidos até o momento por políticas humanitárias de inclusão. Países que fecham suas fronteiras e acirram seus discursos em um protecionismo populista e retrógrado.

Ainda não sabemos claramente o que e como isso irá impactar as futuras gerações. O que fazer diante desses dilemas complexos? Que soluções locais podemos dar para questões tão globais? Não vemos saída além daquela que está a nosso alcance, ou seja, permanecer fiéis a nossos princípios éticos e à nossa visão de mundo que se propõe manter uma postura de reflexão e diálogo na inclusão e manejo das diferenças. Estamos alinhados a uma abordagem que questiona a universalidade do entendimento dos fenômenos e propõe entendê-los como construções sociais. É a partir dessa perspectiva que vamos transitar para poder lidar com discursos universalistas que não reconhecem a singularidade e a diferença, para incluir a voz da minoria.

Gergen (1994) entende o conhecimento como algo a ser construído conjuntamente, entre pessoas inseridas dentro de um contexto, social e político. Sob esta perspectiva, ao mesmo tempo em que somos atores sociais também somos coautores desta realidade compartilhada nas interações. Para Spink e Spink (2014), a pesquisa, como produção de conhecimento, tem uma vertente dialógica, a ética pode ser vista como intersubjetiva, e como uma ação política. Requer uma noção de cuidado, mas não um cuidar do outro, e sim um cuidar de si, criando espaços de reflexão que propiciem o fortalecimento das habilidades de um cuidar coletivo.

Schnitman expressa esta visão dialógica de forma clara:

A ética torna-se um exercício constante de reflexão sobre como construímos o significado, como nos relacionamos e como exploramos novos espaços relacionais para recriar significados. Novas formas de coordenação de ações e inteligibilidades emergem através da ressignificação de nossos modos de vida. As ressignificações são a tarefa dos 
sujeitos em relação, evoluindo juntos. Linguagem, ações e relacionamentos estão entrelaçados e incorporados em jogos relacionais que são constitutivos de nossas vidas; esses jogos nos limitam tanto quanto abrem possibilidades para nós. (Schnitman, 2008, p. 18)

A autora acima citada se refere à ética-em-ação, ou seja, a partir da exploração de nossos jogos de linguagem somos capazes de reconhecer nossas possibilidades relacionais, a forma como produzimos e criamos o conhecimento. Em uma postura generativa, criamos e inovamos ao participar dos diversos jogos de linguagem, para transcender os limites e gerar novas possibilidades. Fazemos escolhas quando entramos em conversações. $\mathrm{O}$ profissional precisa estar atento àquilo que propõe nos encontros dialógicos, que jogo abre, como são recebidas suas propostas, de que lugar elas estão sendo feitas.

A ética é vista como algo que fazemos, mais do que algo que pensamos. Por isso o compromisso na forma de como fazemos, o que fazemos, e a reflexão sobre a origem de nossos pressupostos sobre produção de conhecimento e sobre nossas intenções na intervenção social.

Esta perspectiva ética norteia nosso trabalho dentro do núcleo de mediação, tanto no atendimento aos consultantes, quanto no momento da intervisão. Ao valorizar a ética relacional, estamos cientes de que nossas descrições de mundo são geradoras de significados, portanto, compreender o outro a partir do que se constrói na relação, dar voz às diferenças e dissonâncias é a marca da condução do processo; dentro desta abordagem temos como meta favorecer autonomia e protagonismo dos participantes.
Gergen (2016) corrobora esta perspectiva quando refere que o desafio na relação com os consultantes é desenvolver a prática de uma ética relacional que se mova em direção à responsabilidade relacional, ou seja, formas de intervenção que valorizem primordialmente o processo gerador da relação em si. Poder sair dos mundos particulares em que vivemos e construir pontes de significados entre eles. Resistir à tentação de estar certos, de saber, de julgar e colonizar a mente do consultante. A ética relacional é alcançada dentro de um processo contínuo de se relacionar. Ao buscar esta forma de interação podemos ajudar a construir futuros mais inclusivos e respeitosos.

\section{IMPLANTAÇÃO DO NÚCLEO DE MEDIAÇÃO INSTITUTO NOOS}

Os valores éticos descritos acima nos conduzem para uma perspectiva dialógica de entendimento das diferenças entre as pessoas. Em nossa cultura temos lidado com as adversidades de diversos modos, que vão desde a negação até a punição dos envolvidos. No entanto, nem sempre estas formas habitualmente usadas têm sido efetivas na resolução do conflito e nem proporcionado um aprendizado para lidarmos com ele em situações futuras.

Algumas metodologias têm sido desenvolvidas para a resolução alternativa de conflito, entre elas a mediação, que visa de forma colaborativa a que as pessoas envolvidas possam ampliar sua compreensão e ter o reconhecimento dos participantes e, a partir de diálogos colaborativos, possam considerar, apesar das diferenças, novas possibilidades e planejar ações conjuntamente se responsabilizando por suas decisões e acordos firmados (Schnitman, 1999). 
No Brasil, a partir de 2016, a mediação ganha força e destaque ao ser inserida no novo Código de Processo Civil como parte integrante dos processos cíveis, sendo praticada de forma voluntária nos fóruns e promotorias, assim como em escritórios jurídicos particulares de forma remunerada. Com isto, ganha maior destaque e visibilidade para o público em geral, configurando-se como nova possibilidade de resolver problemas. Essa abordagem trabalha para restabelecer a comunicação que se encontra interrompida. Entende que conflitos são construídos na comunicação, portanto, é no diálogo relacional que eles podem ser resolvidos.

A formação dos mediadores do Núcleo Noos é em mediação transformativa desenvolvida pelos teóricos Bush e Folger (1999) e tem seu foco na capacidade dos participantes de tomar consciência, recuperar o poder e reconhecimento, para negociar com êxito a compreensão de si, do outro e da situação, ao mesmo tempo em que lidam com questões concretas e alcançam acordos.

Tem como aspectos importantes de sua metodologia:

- A comunicação - centrada no diálogo e no caráter relacional.

- Autodeterminação das partes (a decisão de escolher) o acordo como uma escolha pessoal mobiliza as partes a usarem seus próprios recursos para alcançarem seu objetivo.

- Baseada no empowerment, ou seja, reconhecer-se no processo como protagonista.

- A promoção do reconhecimento do outro - empatia.

- Coprotagonismo - reconhecer-se como parte do conflito, portanto, parte da solução.
O processo de mediação dentro dessa abordagem objetiva a transformação da relação entre as pessoas através de um diálogo colaborativo, que possibilita que estas reconheçam seus recursos e implicação no processo, flexibilizando os posicionamentos adversariais e favorecendo que soluções criativas aflorem numa visão ganha-ganha. Dessa forma, reconhece os momentos únicos como oportunidade de mudança e propõe que as inovações emergentes do processo sejam testadas, num processo de pesquisa-ação, para que os participantes possam implementar e testar as novidades que aparecem como possibilidade de mudança. Assim, os envolvidos participam ativamente do processo responsabilizando-se pelas decisões e opções tomadas, no que chamamos de empoderamento.

Acordos firmados com essas bases têm maior chance de serem duradouros, uma vez que os envolvidos se sentem responsáveis e reconhecidos no processo. Participar de uma mediação que ofereça uma outra maneira de conversar possibilita que os integrantes se vinculem e as diferenças não representem uma ameaça, mas sim, uma oportunidade de ampliar e conceber novos caminhos. Criar possibilidades para encontrar e implementar acordos em uma visão ganha-ganha promove um aprendizado que não se restringe ao processo, é um meta aprendizado que é levado para a vida.

\section{O PROCESSO DE CRIAÇÃO DO NÚCLEO DE MEDIAÇÃO NO NOOS - MOMENTOS GENERATIVOS}

Inicialmente, enviamos por e-mail um convite para alguns mediadores da nossa rede, para que fossem conhecer o Noos e nossa proposta de trabalho. 
Estas pessoas demonstraram interesse em aderir ao Núcleo, pois pretendiam praticar a mediação e desejavam participar de um grupo de supervisão dentro de uma Instituição. Importante ressaltar que todos estamos vinculados ao Instituto de forma voluntária. O pagamento feito pelas famílias é revertido para o sustento da instituição.

Para pertencer ao grupo, o mediador deve ser formado pelos cursos credenciados no Núcleo Permanente de Métodos Consensuais de Solução de Conflitos (NUPEMEC) e tornar-se associado colaborativo do Instituto Noos, que implica ter as seguintes disponibilidades: horário para o atendimento e duas horas mensais para encontros com a equipe de mediadores juntamente com a coordenação.

A equipe de mediação formou-se em 2017, inicialmente com 9 mediadores e, atualmente, é composta por 13 pessoas. Os coordenadores, Adriana Lima, Ana Luisa Coutinho, Gabriela Leifert e Roberto Costard, zelam pela qualidade, cumprimento e organização dos processos que envolvem os atendimentos e a equipe. No Instituto temos recebido casos de ex-casais, mãe e filhos, pais e alunos em conflito com escola, família com idosos e outros tipos de situações conflitivas.

Ao nos reunirmos para formar e coordenar o núcleo de mediação Noos, partimos de alguns critérios norteadores do nosso trabalho. O primeiro deles, como já foi mencionado anteriormente, prevê que, para fazer parte da equipe, o mediador precisa ter formação em mediação transformativa. Como primordialmente nossa intervenção em mediação é na família, temos que ter especial cuidado com o vínculo das pessoas mediadas, na medida em que elas permanecem em contínuo contato ao longo do tem- po. Isto requer uma formação específica por parte do mediador, onde o foco não será somente o acordo, mas a melhoria da comunicação e do vínculo das pessoas envolvidas. Pela natureza dos casos encaminhados e com vistas à criação de um campo comum de entendimento entre todos os participantes, tomamos especial cuidado na triagem de nossa equipe. Outro critério, que reforça a atenção com a equipe, é a necessidade de participar da reunião de intervisão que acontece mensalmente, no intuito de propiciar o aprimoramento da prática e pela crença na importância da colaboração de todos para o desenvolvimento da equipe. Nossa proposta de trabalho em equipe muito se assemelha ao modelo da Comunidade de Prática e Comunidade de Aprendizagem descrito pelos pesquisadores cubanos Garcia e Russo (2012). Mais adiante iremos traçar alguns paralelos que consideramos importantes entre os escritos desses investigadores e nossa experiência.

Em nosso primeiro encontro, utilizamos a técnica da Investigação Apreciativa $^{1}$ para as apresentações, com a intenção de acolher o grupo e iluminar o melhor de cada um no fazer profissional. Para tanto, foi pedido que se organizassem em duplas e contassem para seu parceiro uma história de sucesso na prática da mediação, bem como fizessem uma pequena apresentação de si. Este exercício tem alguns propósitos; um deles é iniciar o conhecimento e reconhecimento do grupo a partir de uma história de sucesso, o que propicia na equipe um clima de alegria e descontração, pois todos são apresentados por um "saber fazer" ou "fazer bem". Outro é promover uma escuta ativa do colega, pois ele terá que escolher do que está sendo narrado uma forma de apresentação do parceiro.
${ }^{1}$ I.A., mais comumente utilizado no âmbito organizacional, se propõe a identificar e conectar-se aos aspectos positivos dos indivíduos e organizações, de modo a acentuar a visão de mudança. Cooperrider, D. L., Whitney, D., \& Stravos, J.M. (2009). Ver mais: http://www. scielo.br/scielo.php?pid=S01 0271822010000300020\&scri pt=sci_abstract\&tlng $=p t$ 
Escolhemos esta prática por compartilharmos a crença na inteligência coletiva, ou seja, acreditamos que, embora um indivíduo possa ter muitos recursos individualmente, quando ele se junta a outros e compartilha ativa e criativamente suas narrativas, os recursos se fortalecem e amplificam os significados, gerando novas e melhores possibilidades de ação. Consideramos que iniciar um grupo a partir de uma perspectiva apreciativa tem um caráter generativo, pois aponta para a potencialidade e promove o que todos têm de melhor em si, tornando as pessoas agentes de seus processos de desenvolvimento, uma vez que se apropriam de seus recursos.

Como refere Schnitman (2015b):

Os processos generativos e apreciativos são transformadores e propiciam a capacidade dos participantes de aprender sobre si mesmos, os dilemas que enfrentam e os processos nos quais estão envolvidos, bem como as oportunidades, resultados e possibilidades que esses processos oferecem. Essas abordagens reposicionam as pessoas nos relacionamentos como sujeitos-agentes que podem aproveitar sua capacidade de aprender e inovar para lidar com os diversos problemas que a vida apresenta e construir futuros alternativos. (p.1)

Neste sentido, escolhemos iniciar a formação desse grupo de trabalho a partir de suas fortalezas criando um clima de cooperação e entendimento que favorece o diálogo e a troca de sa-

2 Para informações complementares ver 0 artigo: Mindfulness na construção terapêutica do espaço comunicativo baseado na atenção conjunta ao corpo. http://www.revistanps.com.br/nps/article/ view/403 vo na tentativa de engajar as pessoas ativamente no trabalho coletivo. Em todas as reuniões são feitas atas, nas quais se relata o que foi construído conjuntamente, com linguagem acolhedora e inclusiva, ressaltando que a ausência dos que não puderam comparecer foi sentida. Dessa forma, engajamos os ausentes ativamente de forma abrangente, não gerando sentimento de culpa ou cobrança a posteriori. Este acolhimento tem incentivado uma maior participação, evitando faltas, há uma visível satisfação de todos nós, coordenadores e equipe, por estar ali, compartilhando um espaço de trocas e aprendizagens.

Consequentemente, este clima de confiança e pertencimento tem favorecido a construção de boas parcerias para os atendimentos que são feitos por duplas de mediadores. Arandes, Davila, Baesz, e Garcia (2015) referem que, para fomentar a colaboração e cumprir os acordos que estabelecemos, é necessário assumir uma postura relacional e dialógica que privilegie a curiosidade, humor, sensibilidade no momento interativo em uma posição de não saber. Partilhamos da crença que um bom clima relacional auxilia na colaboração do trabalho em equipe. Constatamos que as pessoas que participam dessa equipe sentem a mesma gratidão e empatia que nós coordenadores/as, pois percebem que suas qualidades são validadas de forma apreciativa e a cada encontro buscamos meios de surpreender e retirar o melhor de todos, na certeza de buscar a inteligência coletiva de forma horizontal.

Costumamos fazer uma prática de mindfulness no início de cada encontro. Mindfulness ${ }^{2}$ é uma prática de meditação budista que tem como função proporcionar calma e claridade à mente a fim de aquietar as tensões cotidianas e promover condições de es- 
tar no momento presente observando o mundo livre de preconceitos, projeções e reações emocionais (Fronsdsal, 2011). Edgardo Morales Arandes (em comunicação pessoal, 2017) introduziu-nos a essa prática, como forma de conduzir o grupo para um estado de atenção plena, a fim de promover relaxamento e ampliar a capacidade de percepção e entendimento dos participantes e, consequentemente, favorecer o processo de aprendizagem e interação. Utilizar essa prática no início de cada encontro tem se mostrado útil, pois coloca todos em uma condição emocional mais conectada aos objetivos presentes, que podem ser estudo de um texto ou o relato de um caso para intervisão.

\section{A INTERVISÃO COMO UM ESPAÇO GENERATIVO}

A intervisão é um modelo de supervisão onde os participantes assumem uma posição horizontal, privilegiando uma situação de autocomposição e autoaprendizagem. O "supervisor" sai da cadeira de formador e toma seu lugar dentro do círculo de diálogo, atuando como um facilitador, saindo do lugar de "expert". Essa postura tem sua origem nos pressupostos que norteiam a perspectiva construcionista, entre eles a ênfase na construção social do conhecimento, questionando a universalidade do entendimento dos fenômenos e entendendo-os como construções sociais. É uma perspectiva que caracteriza o destaque dado à linguagem e à interação entre as pessoas na compreensão dos processos de construção de sentido, considerando que "tanto as palavras que usamos como o nome que atribuímos uns aos outros são usados para efetuar relações" (Gergen \& Gergen, 2010 p.24).
Estamos imersos e nos constituímos na linguagem, em histórias narradas, histórias que nos contam e contamos sobre nós e sobre o mundo. Na busca por darmos significado às experiências da vida, criamos narrativas a respeito de nós mesmos que acabam por formar a história de nossa vida. Dessa forma, o Construcionismo Social entende que nossas explicações sobre o mundo são frutos da coordenação humana, do significado construído em relacionamentos humanos. Considera que é através da nossa participação nas práticas discursivas, social e culturalmente situadas que produzimos conjuntamente descrições da realidade (Gergen, 1994). Adotar essa perspectiva traz implicações para o papel do profissional, que passa a ter seu foco maior no processo e não em objetivos predeterminados, tais como a procura da causa e da verdade. Seu papel passa a ser o de um parceiro conversacional (Anderson \& Goolishian, 1998). Isto promove a compreensão de que todos temos a contribuir e aprender com o saber compartilhado, amplia a autonomia e a responsabilização da equipe pelo seu próprio desenvolvimento, além de contribuir para o crescimento dos membros individualmente.

Nossa proposta de intervisão muito se assemelha ao modelo de formação de trabalho em equipe da comunidade de prática e comunidade de aprendizagem descrito por García e Russo (2012). Eles descrevem a Comunidade de Prática como uma rede de atividades e ações interdependentes e autogeridas que vinculam pessoas, significados e ações concretas em trocas internas e com o ambiente. Por sua vez, a comunidade de aprendizagem entende a compreensão da natureza social da aprendizagem. $\mathrm{Na}$ comunidade de aprendizagem os membros estão genuinamente 
envolvidos em manter interações constantes para aprender e melhorar a prática, o que se converte em uma meta de desenvolvimento constante.

Não existe aprendizagem efetiva sem autorregulação, a aprendizagem efetiva humaniza. Assim, três critérios de avaliação são usados num processo de desenvolvimento de uma comunidade de aprendizagem: participação; prática; identidade e sentimento de pertencimento à comunidade. Em resumo, pode-se descrever a comunidade de prática como a participação em uma prática que produz mudanças em seus membros, tanto nos significados que elaboram, como na identidade individual e grupal que eles constrõem. Alinhamos nossa forma de criar e trabalhar com a equipe a estas ideias de práticas que propõem a coconstrução de significados e a autorregulação dos mesmos em um clima de desenvolvimento e geração de espaços colaborativos e humanizantes.

Portanto, proporcionar a multivocalidade da equipe fortalece a maneira de trabalhar de cada um ao compartilhar os saberes coletivos em um ambiente de respeito e confiança, estimula o vínculo entre os colegas e aprimora a qualidade dos atendimentos. Nesses espaços, os participantes interpretam, constrõem significados e ações juntos e se reconhecem como coparticipantes. Identificamos nesse fazer grupal um espaço generativo de aprendizagem, pois possibilita que os profissionais reflitam sobre o que têm feito, que caminho tomaram, e por qual marco teórico estão orientados. São espaços de interação dialógica de ação social coordendada que insere os integrantes como investigadores em ação da situação que se propõem estudar e transformar (Schnitman, 2015a). Refletir em ação permite identificar um conjunto de saberes novos e de saberes sobre saberes, tanto para o profissional como para os consultantes.

Promover esse aprendizado em ação de forma generativa tem possibilitado uma maior integração da equipe com parcerias frutíferas e colaborativas, alinhando os pressupostos que orientam a prática.

A perspectiva generativa nos oferece a noção de cinco saberes que podem nos servir como um mapa relacional norteador de nosso encontro com os mediados e também de nossa reflexão na intervisão.

São eles:

- Saber o que fazer e saber como fazer - como vincular ações específicas com o contexto e com as possibilidades;

- Saber expressar-se e se fazer compreender - permite criar coordenações e escolher as possibilidades;

- Saber posicionar-se nas diferentes dimensões do processo;

- Saber de si em contexto - é acompanhado do saber emocional que oferece um sinalizador para evitar campos minados e escolher caminhos que ofereçam oportunidades;

- Saber relacional - facilita a construção do próprio e do comum frente às necessidades para além das diferenças (Schnitman, 2011, p.17).

Refletir sobre estes cinco saberes nos parece ferramenta fundamental, tanto do ponto de vista do aprendizado, quanto da conscientização destas posições relacionais no encontro com o outro. Esta prática promove um tipo de diálogo que vai além dos interesses individuais e favorece a criação de um campo de novas possibilidades em que os participantes se reconhecem ca- 
pazes de trabalhar com o emergente (Schnitman, 2000).

Os casos que são apresentados na intervisão são enriquecidos pelo olhar apreciativo dos colegas que observam pontos de abertura para novas possibilidades ainda não exploradas, gerando uma multiplicidade de opções de caminhos que os mediadores levam para oferecer aos clientes no processo. Por conseguinte, temos constatado que as mediações têm alcançado resultados frutíferos para seus envolvidos, promovendo reflexão, reconhecimento e transformação nas relações.

Além disto, a intervisão tem a finalidade de oferecer um espaço seguro, afetivo e de suporte para que os mediadores consigam acolher as demandas de sofrimento, conflito e vulnerabilidade que enfrentam junto aos casos atendidos. Ao descrever essa forma de trabalhar em intervisão, pudemos observar as semelhanças descritas no trabalho do operador generativo proposto pelo modelo generativo.

O operador generativo é um facilitador, um moderador; ele coordena as interações entre as pessoas promovendo novas possibilidades de diálogo; precisa estar muito conectado com os consultantes e com tudo que está acontecendo no campo. A perspectiva da presença plena o coloca atento para si mesmo, suas reações corporais, as interações não verbais, as emoções, o clima relacional e o diálogo que está sendo travado, compreendendo que uma consulta ocorre em um tempo multitemporal. A noção de tempo carrega em si a dimensão da complexidade das relações. O operador generativo encoraja os participantes a compartilharem suas experiências sempre em primeira pessoa, promove o reconhecimento de recursos através de uma perspectiva apreciativa dos consultantes, ilumina situações ou fatos que haviam passa- do despercebidos, encontrando novas possibilidades de diálogo, procura ter escuta voltada para as exceções, pequenos eventos que não são valorizados, presta atenção a aspectos verbais e não verbais da comunicação (Schnitman, 2016).

O processo dialógico é validado pelas respostas dos consultantes; nestas respostas, o operador generativo considera quais proposições oferecem portas de entrada que sejam aceitáveis para os consultantes. Os consultantes, por sua vez, oferecem ativamente experiências, inquietações, elaborações que o profissional incorpora no diálogo, sempre em uma postura inclusiva e de respeito

Apoia-se, portanto, em perguntas generativas como ferramenta básica na condução das interlocuções, tem como objetivo o reconhecimento de novas possibilidades, a ampliação das condições dos participantes em ter contato com o novo, o convite para identificar novos ciclos generativos, poder pensar sobre eles e também sobre a participação de cada um na construção de alternativas. A seguir apresentamos algumas perguntas que muito nos ajudam na compreensão e condução das intervisões. Nosso interesse, ao longo da condução dos trabalhos, é poder implementar cada vez mais estas premissas e colocá-las em prática de forma sistematizada, com a intenção de assumir o rol de operador generativo na prática de forma plena. Perguntas generativas que podem promover o reconhecimento daquilo que não é usual (Schnitman \& García, 2013):

- De que maneira você se sentiu escutado?

- De que maneira impacta o que você enxergou de diferente na posição do outro em relação às posições prévias? 
- Em quais situações novas você se vê envolvido?

- Como cada participante, especificamente, poderia se envolver na construção de possibilidades?

- De que maneira ele/ela poderia fazer isso?

- O que poderia facilitar uma mudança favorável?

- Como tais mudanças poderiam ser implementadas?

Também podem ser utilizadas para identificar o conhecimento implícito dos participantes:

- Quais novas habilidades dispõe?

- Como elas se originaram?

- Como você reconheceu os novos desenvolvimentos, possibilidades e perspectivas?

- Que oportunidades foram abertas?

- Como poderiam ser implementadas?

- De que forma você e os demais poderiam contribuir à implementação e manutenção destas mudanças?

- Que nova direção/ação ela propõe?

- Como você a descreveria?

Acreditamos que focalizar de onde partimos se torna valioso e demanda responsabilidade quando tratamos com seres humanos. Assim a gestão de uma equipe de intervisão se assemelha em grande parte à forma de trabalhar de um operador generativo.

\section{CONSIDERAÇÕES FINAIS}

Iniciar um núcleo de atendimento que tem como objetivo o trabalho com Mediação em uma abordagem transformativa apresenta-se como um desafio e nos coloca diante da escolha dos marcos teóricos a serem adotados na construção e condução da equipe. As perguntas que surgem a seguir são: Quais influências experimentamos ao longo de nosso caminho e como materializá-las de modo a dar-lhes vida e voz para torná-las coerentes com nossos propósitos?

A formação dessa equipe e o desenrolar desse projeto tiveram como influências teóricas a abordagem apreciativa e, em particular, a prática generativa. Esses referenciais teóricos são identificados em muitas das nossas posturas e escolhas. Estas linhas teóricas privilegiam a criatividade, a inovação, as competências ao invés do déficit. Concentram seus esforços, alinham suas forças nos processos dialógicos e na coconstrução de significados em uma postura de não saber, privilegiando as exceções e o inusitado na interação. O supervisor se transforma em um facilitador da comunicação, assumindo seu lugar dentro do grupo de forma horizontal, promovendo, a partir de uma postura de atenção plena, a integração das vozes de todos, iluminando a potencialidade de cada um dentro do grupo. $\mathrm{O}$ fazer é algo compartilhado, sem hierarquia em um clima colaborativo, de bom humor e afetividade. Trabalhar com criatividade e inovação torna-se a marca registrada desse operador que se encarrega de ser um facilitador do processo nos encontros de intervisão. Além dos efeitos generativos na construção e gestão da equipe, constatamos que nosso formato de intervisão tem proporcionado mudanças significativas tanto na condução dos processos de mediação quanto na vida dos participantes. A ética relacional se tornou uma premissa a ser compartilhada, pois entendemos que 
a nossa prática é acima de tudo um ato político, que demanda critério e reflexão sobre o significado que atribuímos a nossas ações.

Descrevemos a gestão de conhecimento como a de um grupo autogerido, onde as aprendizagens acontecem enquanto se pratica a ação. Semelhante ao modelo da comunidade de prática e comunidade de aprendizagem, ou seja, a aprendizagem do grupo se dá dentro de uma rede de ações interdependentes que vinculam pessoas, significados, propósitos e meios materiais, criando condições para manutenção da produção continuada de conhecimento. Trabalhamos no presente com foco no futuro, sem desconsiderar as aprendizagens passadas. Desta maneira, iluminar o que está por vir nos conduz ativamente ao encontro da incerteza, na certeza de construir relações mais integradas, que gerem saídas criativas para os dilemas relacionais que se apresentam. Compartilhar a crença na capacidade das pessoas de serem agentes de seus destinos através de um processo dialógico foi fundamental para implementar o Núcleo de Mediação. Poder descrever como reconhecemos o olhar generativo na maior parte de ações que tomamos nos enche de orgulho e gratidão pelo aprendizado realizado.

Trabalho para obtenção do Título de Operador Generativo.

Parte das exigências de obtenção do título de Operador Generativo do curso internacional ministrado online por Dora Schnitman e Edgardo Morales e coordenação de Silvia Crescini, ano 2017.

\section{REFERÊNCIAS}

Anderson, H. \& Goolishian, H. (1998). O cliente é o especialista: uma abordagem para terapia a partir de uma posição de não saber. In S. McNamee \& K. Gergen (Orgs.), Terapia como Construção Social (pp.34-50) Porto Alegre: Artes Médicas.

Arandes, E.M, Davila, P.T., Baesz, S. S., \&Garcia, Z.A. (2015) Diálogo, Performatividad em psicoterapia. In D. F. Schnitman (Ed.), Diálogos para la transformación. Experienciais y otras intervenciones psicosociales em Iberoamerica (Vol. 1, pp.85-104). Ohio: Taos Institute.

Bush,R.A. \&Folger,J,P. (1999). Mediação transformativa e intervenção de terceiros: as marcas registradas de um profissional transformador. In D. Schnitman \& S. Litllejohn (Orgs.), Novos Paradigmas em Mediação (pp. 85-124). Porto Alegre: Artemed.

Cooperrider,D. L., Withney, D.s\&Stravos, J. M. (2009). Manual de investigação apreciativa. Rio de Janeiro: Qualimark.

Fronsdal,G. (2011).Viviendo en el presente. Ensayos sobre la practica Budista.USA:Tranquil Books.

Garcia,R.M. \& Russo, R.C. (2012) Comunidad de practica y Comunidad de aprendizaje. In D. F. Schnitman (Ed.),Dialogos para la transformaion. Experiencias y otras intervenciones psicosociales em terapia em Iberoamerica (Vol. 1, pp. 37-50). Ohio: Taos Institute.

Gergen, J.K.(1994). The communal Basis of Social knowledge. In Toward Transformation in Social Knowledge ( $2^{\text {a }}$ ed., pp. 1-57). Londres: Sages Publications.

Gergen, J.K. (2016). Rumo a uma ética relacional para a pratica terapêutica. Nova Perspectiva Sistêmica, 21(56), 
11-21.http://www.revistanps.com. br/nps/article/view/237

Gergen, J.K.\&Gergen, M. (2010).Construcionismo Social: um convite ao diálogo. Rio de Janeiro: Instituto Noos.

Schnitman, D.F. (1999). Novos paradigmas na resolução de conflitos. In D. F. Schnitman \& S. Littlejohn (Orgs.), Novos paradigmas em mediação (pp 17-28). Porto Alegre: Artmed.

Schnitman, D. (2000). Terapia como Prática Social Generativa: perspectivas e habilidades. In H. M.Cruz (Org.), Papai, Mamãe, Você e Eu? (pp. 291-313). São Paulo: Casa do Psicólogo.

Schnitman,D. F. (2008). "Questionário generativo em terapia”. Pensando Familias, 12 (1), 11-26. http://www.fundacioninterfas.org/ capacitacion/wpcontent/uploads/2016/05/10.QuestionarioGenerat.pdf

Schnitman, D. (2011). Processo generative e práticas dialógicas. Revista Nova Perspectiva Sistêmica, 20(41), 9-34. http://www.revistanps.com. br/nps/article/view/199/180

Schnitman, D. (2015a). Diálogos para la Transformación. Experiencias en terapia y otras intervenciones en Iberoamérica (Vol. 1). Ohio, USA: Taos Institute.

Schnitman, D. (2015b). Appreciative and Generative Perspectives, Points of Convergence in a Productive Dialogue.AI Practitioner, 17(1), 15-21.

Schnitman, D. (2016). Perspectiva e Prática Generativa. Revista Nova Perspectiva Sistêmica, 25(56), 55-75. http://www.revistanps.com.br/nps/ article/view/241/233

Schnitman, D. \& Garcia, M. R. M. (2013). Enfrentamento generativo e desenvolvimento comunitário. Revista Nova Perspectiva Sistêmica, 22(45),
88-113. http://www.revistanps.com. br/nps/article/view/122

Spink, M. J. P. \& Spink, P. K. (2014). Produzir conhecimento não é um ato banal: olhar (pós) construcionista sobre a ética na pesquisa. In Construcionismo Social: discurso, pratica e produção do conhecimento (pp 133-149). Rio de Janeiro: Instituto NOOS, pp.133-149.

\section{ANA LUISA ALMEIDA PRADO DE ANDRADE COUTINHO}

Terapeuta de família, mediadora, coordenadora do Núcleo de Mediação Noos, gestora Noos.

E-mail: analuisacoutinho27@gmail.com

\section{MARIA GABRIELA MANTAUT LEIFERT}

Psicóloga clínica, terapeuta de família, mediadora, coordenadora do Núcleo de Mediação Noos, gestora Noos, coordenadora da Clínica Social APTF. E-mail: $\underline{\text { mgmleifert@gmail.com }}$ 